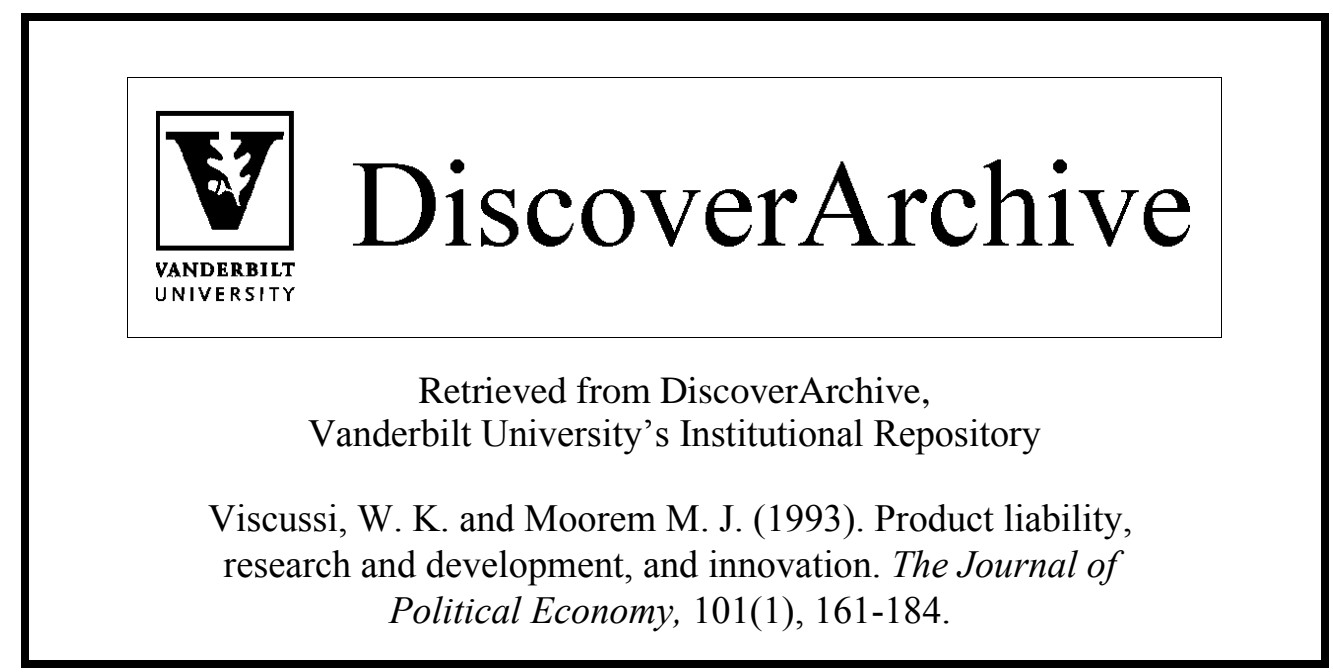




\section{Product Liability, Research and Development, and Innovation}

\section{W. Kip Viscusi and Michael J. Moore}

Duke University

Product liability ideally should promote efficient levels of product safety, but misdirected liability efforts may depress beneficial innovations. This paper examines these competing effects of liability costs on product R \& D intensity and new product introductions by manufacturing firms. At low to moderate levels of expected liability costs, there is a positive effect of liability costs on product innovation. At very high levels of liability costs, the effect is negative. At the sample mean, liability costs increase $\mathrm{R} \& \mathrm{D}$ intensity by 15 percent. The greater linkage of these effects to product $R \& D$ rather than process $\mathrm{R} \& \mathrm{D}$ is consistent with the increased prominence of the design defect doctrine.

\section{Introduction}

Management decisions with respect to the product mix are subject to a variety of uncertainties. One class of these uncertainties pertains to the regulatory environment of the firm, including incentives generated by direct government regulation and civil liability. Defective products may generate enormous legal liabilities, potentially undermining not only the profitability of the product but possibly the firm itself. In this paper, we explore the role of the product liability system in affecting new product development decisions.

In recent years, widespread attention has been devoted to the liabil-

Helpful comments were provided by George J. Stigler, an anonymous referee, and participants in seminars at the National Bureau of Economic Research Industrial Organization Workshop, the Brookings Institution Conference on Civil Liability, and the Law and Economic Workshop at the University of Michigan. David Anderson provided excellent research assistance. This research was supported by the National Science Foundation (grant SES-8823002). 
ity crisis. ${ }^{1}$ Product liability litigation increased dramatically, with the number of product liability cases alleging personal injury filed in the federal courts rising from 2,393 in 1975 to 13,408 in 1989. Liability insurance costs also escalated, as general liability insurance premiums increased sixfold from 1975 to 1988.

Several changes in liability doctrines over the past three decades contributed to this growth. First, most jurisdictions adopted strict liability, which expands the range of situations in which the producer can be found liable. Courts now view producers as serving, in part, as product risk insurers. Second, the courts greatly expanded the doctrine of design defects and the role of hazard warnings. Whereas product liability cases formerly focused on manufacturing defects, a firm could now be found liable for a broad range of design defects. By doing so, the courts in effect took on functions similar to those of product risk regulatory agencies. Third, the emergence of mass toxic torts generated litigation on an unprecedented scale. There are over 100,000 claimants each in the lines of litigation involving asbestos, Agent Orange, and the Dalkon Shield.

The increased emphasis on design defects altered the industrial incidence of product liability costs. "Manufacturing defect" cases concentrated liability among older firms that manufactured their products in a negligent manner, perhaps because of outmoded technologies or inadequate quality control. In contrast, design defect cases affect all segments of the market. The least innovative firms incur liability costs because their products do not reflect the industry's state of the art in safety. Highly innovative firms that introduce new product designs with uncertain safety implications run substantial liability risks as well.

High expected product liability costs may depress innovation. The Monsanto Company decided not to market its already patented phosphate fiber asbestos substitute because Monsanto "was not prepared to accept the potential product liability risks associated with marketing the reinforcing fiber, no matter how safe it may be" (Business Insurance, July 20, 1989, p. 3). Similarly, a National Academy of Sciences (1990) panel concluded that U.S. pharmaceutical firms terminated research on contraceptive products in part because the liability risks were too great. The market for vaccines has also been hard hit, as rising liability costs decreased the number of firms producing vaccines for five serious childhood diseases from 13 to three during the 1980 s. $^{2}$ U.S. private aircraft production plummeted over the same

\footnotetext{
${ }^{1}$ The subsequent paragraphs draw on a variety of material pertaining to the dimension of the liability crisis. See Viscusi $(1991 a, 1991 b)$ for documentation.

${ }^{2}$ See Viscusi $(1990,1991 a)$. Kitch (1985) provides a detailed perspective on how liability has affected a variety of specific vaccines.
} 
period, with many industry officials citing rising liability costs as a major contributing factor.

To move beyond these anecdotes and case studies, our empirical approach considers the relationship between product liability insurance costs and various aspects of innovation using a large data set on firm behavior. The time period we consider, $1980-84$, follows by two decades the emergence of the design defect doctrine and the initial period of adoption of strict liability. As a result, the liability regime reflected in the data should fully capture the behavior influenced by the central doctrines in modern product liability law.

Supporters of the current liability regime claim that liability costs provide incentives for introducing safer products and eliminating unsafe products. Liability critics suggest that the cost increases discourage innovation more generally. Although we can ascertain the nature of product research and development decisions most strongly influenced by liability costs, the efficiency properties of these results are less clear. Full resolution of the debate on efficiency requires a product-specific assessment of the risks and benefits of different designs. Some products may not provide an efficient level of safety and should be either redesigned or perhaps not marketed at all. In a perfectly competitive market, fully informed consumers will purchase only products that provide an efficient level of product safety. If, however, substantial impediments prevent efficient operation, such as systematic misperception of accident risks or substantial consumer search costs, market outcomes will not be optimal.

Tort liability can potentially foster greater efficiency in these contexts, particularly since the negligence doctrine and the risk-utility test for strict liability are analogous to benefit-cost tests for product safety. ${ }^{3}$ However, the strict liability test imposes additional obligations that require the producer to insure the victim's losses, so that the standard may be binding even when the firm's level of precaution is efficient. ${ }^{4}$ Moreover, some legal scholars raise the fundamental issue of whether juries are qualified to assess the economic merits of alternative product designs. These ambiguities make it difficult to ascribe efficiency properties to the product liability-innovation linkage. Our primary emphasis will be on documenting the effects of product liability rather than on drawing specific conclusions regarding their economic efficiency.

The analysis focuses on product $\mathrm{R} \& \mathrm{D}$ intensity as the measure of

\footnotetext{
${ }^{3}$ Much of the work of Landes and Posner (1987) and Shavell (1987) deals with the efficiency properties of many legal rules in this area.

${ }^{4}$ Viscusi $(1991 b)$ explores in greater detail the inadequacies of the risk-utility test from an efficiency standpoint and proposes a reformulation of that test based on an efficiency-oriented approach.
} 
innovative activity and on two different measures of product liability costs. Most noteworthy is the robustness of the findings across the different dimensions of the product liability-innovation linkage. For the majority of business units in our sample, product liability increases product $R \& D$ intensity. This result lends support to the claim that higher liability burdens provide incentives for product safety improvements. There is, however, a nonlinearity in the product liability-innovation relationship. At high levels of liability costs, liability reduces innovative activity. In the third general empirical result, more pronounced effects for product innovation relative to process innovation reflect the increasingly prominent role of the design defect doctrine.

\section{Conceptual Framework}

Product liability enters most economic models by simply raising the expected costs associated with product risks. Liability costs play a limited role in models based on risk-neutral consumers acting on perfect information, actuarially fair liability insurance, competitive product markets with horizontal supply curves, and losses that are monetary equivalents. ${ }^{5}$

These conditions are seldom satisfied. Consumer information is not always perfect. Moreover, since health effects often involve losses that alter the structure of utility functions, consumers will value product safety even with full coverage of their financial losses. Product liability cost increases consequently increase the firm's costs and influence its risk-related decisions.

To assess the role of product liability costs, we structure the model in terms of the firm's unit profit function $\pi$, thus focusing on safety and innovation decisions rather than on quantity choice. ${ }^{6}$ The joint products of the firm constitute the choice variables and consist of the level of product safety $s$ and the degree of product novelty $z$. The level of safety equals one minus the probability of injury.

A nonlinear hedonic price function consisting of a base product price $p$, a premium $\alpha z$ for product novelty, and a liability cost $\beta(s, L)$ describes the unit price of the product. Consumers will pay more for product novelty (i.e., $\alpha>0$ ), and we define the scale of the novelty

\footnotetext{
${ }^{5}$ See Spence (1977) for exposition of such a model. See also Oi $(1973,1974)$, Goldberg (1974), and Epple and Raviv (1978).

${ }^{6}$ This simplification follows Spence (1977). Expansion of the model to include a quantity choice is straightforward and yields predictable results: higher liability costs reduce output. However, addition of this consideration complicates the comparative static results by adding a third equation to the system.
} 
variable $z$ with no loss of generality so that the novelty price premium is a simple linear function of $\alpha$ and $z$.

The unit liability cost $\beta(s, L)$ decreases with product safety $\left(\beta_{s}<0\right)$ and increases with the stringency of the liability regime $\left(\beta_{L}>0\right)$. In an absolute liability regime, where firms pay all expected injury costs, a linear formulation in which $\beta(s, L)=(1-s) L$ is appropriate. In practice, various liability rules may make the liability cost function a nonlinear function of the level of safety $s$. Under a negligence standard, no liability exists unless the firm fails to provide a reasonable degree of safety, after which the firm becomes liable for all injury costs (see, e.g., Landes and Posner 1987; Shavell 1987; Polinsky 1989). Even under strict liability, liability on the part of the firm arises only when the product fails a risk-utility test, which entails a balancing of the costs and benefits of greater product safety. ${ }^{7}$ Finally, firms that market risky products potentially subject themselves to punitive damages if they have been particularly remiss in providing for product safety. Another complication is that for very high levels of safety $\beta(s, L)$ may equal zero.

The inputs necessary to produce safety $s$ and product novelty $z$ are given by $g(s, z)$. The input requirements increase at an increasing rate with the value of each joint product (i.e., $g_{s}>0, g_{z}>0, g_{s s}>0$, and $g_{z z}>0$ ). The unit cost of the inputs is $r$.

The firm selects the joint products $s$ and $z$ that maximize unit profits, or

$$
\max _{s, z} \pi=p+\alpha z-\beta(s, L)-r g(s, z),
$$

leading to the first-order condition

$$
\frac{g_{s}}{g_{z}}=\frac{-\beta_{s}}{\alpha} .
$$

Figure 1 sketches the nature of the firm's problem. Suppose that the transformation curve $g_{0}=g(s, z)$ describes the joint product mix for the firm at various possible profit-maximizing levels of safety and novelty. The unit price curve $R_{0}$ is tangent to this transformation curve at the optimal product mix, with the slopes of the transformation curve and the unit price curve given by equation (1). ${ }^{8}$ For simplic-

\footnotetext{
${ }^{7}$ One factor in a risk-utility test is the producer's role as insurer. If this factor is dominant, the risk-utility test becomes an absolute liability standard.

${ }^{8}$ The equation for the constant unit price curve is given by $p_{0}=p+\alpha z-\beta(s, L)$, or

$$
z=\frac{p_{0}-p}{\alpha}+\frac{\beta(s, L)}{\alpha}
$$
}

so that $d z / d s=\beta_{s} / \alpha<0$. 


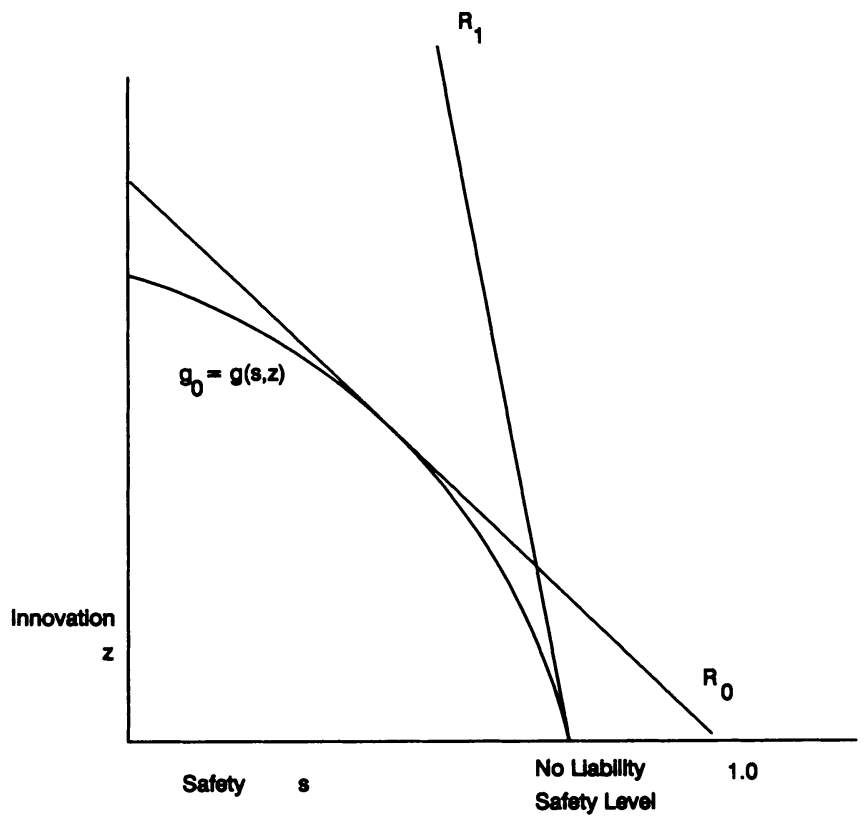

Fig. 1.-Choice of the optimal joint product mix

ity, this diagram illustrates the case in which the expected liability cost is a linear function of the level of risk.

With a very stringent liability regime (i.e., a large value of $L$ ), the unit price curve becomes very steep, taking a form such as $R_{1}$. This situation illustrates a corner solution at which the firm undertakes no product innovation expenditures and undertakes the maximum amount of safety expenditures on the transformation curve $g_{0} \cdot{ }^{9}$ High levels of liability consequently may eliminate all innovation and lead firms to adopt designs without liability costs. Product engineers, for example, frequently note a bias toward accepted but somewhat risky designs rather than designs whose safety level is uncertain relative to the status quo. The observed effect may be withdrawal of the product altogether, as in the case of intrauterine contraceptive devices and some vaccines. These corner solutions play an important role in the empirical analysis.

For interior solutions, the effects of liability $\operatorname{cost} L$ on the choice variables are given by

${ }^{9}$ It may be that with such a low market value of safety the pertinent product transformation curve at the profit-maximizing point will be at a safety level of 1.0 rather than $g_{0}$ in fig. 1 . 


$$
\frac{d s}{d L}=\frac{r g_{z z} \beta_{s L}}{D}
$$

and

$$
\frac{d z}{d L}=\frac{-r g_{s z} \beta_{s L}}{D}
$$

where the determinant $D=\left(r g_{s z}\right)^{2}-r g_{z z}\left(\beta_{s s}+r g_{s s}\right)<0$ at an interior maximum.

The directions of these effects will be apparent if we impose some additional structure. Suppose that $\beta_{s L}<0$, as is the case with the linear liability cost term, $\beta(s, L)=(1-s) L$. Higher liability costs will necessarily raise product safety so that $d s / d L>0$. The product innovation effect depends on the effect of innovation on the firm's ability to produce safety. If innovation enables the firm to increase safety at less cost (i.e., $g_{s z}<0$ ), then $d z / d L>0$. If, however, innovation makes it more difficult for the firm to produce product safety (i.e., $\left.g_{s z}>0\right)$, then $d z / d L<0$. If there is no interaction between safety and novelty in the input requirement function (e.g., $g(s, z)=f(s)+h(z)$ ), then $g_{s z}=0$ and $d z / d L=0$; higher liability costs will affect safety investments but not product novelty. There has also been speculation that juries may be biased against innovative products, controlling for the level of safety and other factors. Such an anti-innovation bias will tend to decrease the incentive to innovate at higher levels of liability cost. $^{10}$

These various results illustrate the mixed nature of the product liability-innovation linkage. Higher liability costs will increase product innovations directly related to safety improvements and also those that introduce new technologies if these technologies decrease the costs of providing safety. However, innovations that do not lower the marginal costs of providing safety will be depressed. In the case of extreme liability costs, product novelty will be eliminated altogether as the firm selects the no-risk corner solution.

The different components of the innovation process-safety innovations and product novelty - may consequently respond differently to increasing liability costs. If we could isolate these components empirically, it would be possible to distinguish the competing effects. Unfortunately, we observe only overall product R \& D expenditures, or total product introductions. The available data do not indicate, for example, whether the new products represent safer variants of existing product designs or new product designs that alter attributes

${ }^{10}$ This variation can be readily incorporated into the model by amending the liability cost term to be $\beta(s, L, z)$, where $\beta_{z}>0$. Equation (1) becomes $g_{s} / g_{z}=-\beta_{s} /\left(\alpha-\beta_{z}\right)$. 
other than safety. Our empirical predictions consequently will be made in terms of the composite of innovative actions.

It should also be emphasized that no value judgments can or should be attached to whatever liability-innovation linkage we identify. Efficiency judgments regarding these outcomes depend on the character of the market failure and the nature of the liability regime-issues that have been explored in detail elsewhere. ${ }^{11}$

\section{The Sample and the Variables}

We draw the data on firm-level decisions used in this study from two primary sources: one pertaining to product decisions and the other to insurance costs. We link these data on the basis of the pertinent three-digit standard industrial classification (SIC) code.

\section{Product Innovation Data}

The product characteristics data consist of a broad panel of U.S. firms' business units known as the Profit Impact of Marketing Strategies (PIMS) data. These data, developed by the Strategic Planning Institute, contain both balance sheet and income statement items for sample lines of business. In addition to these data, the PIMS sample includes information on characteristics of the business unit's industry and a wealth of information on the strategies followed by the respondent firms. The PIMS data have been used by Ravenscraft and Scherer (1982) to study R \& D and by Clark and Griliches (1984), who focused on R \& D and productivity growth. Since the PIMS sample consists primarily of large business units, any inferences drawn from the subsequent results can be made conditional on relatively large size.

The variables drawn from the PIMS data, which table 1 defines, include the $\mathrm{R} \& \mathrm{D}$ and innovation variables and dummy indicators of recent entry or exit by a major competitor. We also considered a measure of the industry long-run growth rate and line of business market share, but neither of these had any effect on R \& D intensity. To control for broad industrywide effects, all estimating equations also include dummy variables indicating whether the line of business manufactures consumer or producer durables or nondurables. Time dummy variables for four of the years in the 1980-84 period control for year-specific cyclical effects.

The unit of observation is the line of business, which PIMS defines

${ }^{11}$ See esp. Oi (1973, 1974), Spence (1977), and Epple and Raviv (1978). See also Landes and Posner (1987), Shavell (1987), Polinsky (1989), and Viscusi (1991b). 
as an operating unit that sells a distinct set of products or services to an identifiable set of customers, in competition with a well-defined set of competitors. The primary dependent variable in the empirical analysis, drawn from the PIMS data, measures dollars spent on product $R$ \& $D$ relative to sales, or product $R \& D$ intensity. Other innovation variables include process $\mathrm{R} \& \mathrm{D}$ intensity, a measure of the percentage of sales due to new products (i.e., those less than 3 years old), and a dummy indicator of whether the line of business does any $\mathrm{R} \& \mathrm{D}$.

Three dummy variables measure the long-run level of $R \& D$ activity for each line of business. The first two of these long-run variables indicate whether the firm benefits substantially from patents on products or processes. These variables measure long-run R \& D capital at the firm level. The third long-run variable indicates the pace of technological change in the industry. The results in Levin et al. (1987) indicate that this latter variable is a better measure of long-run innovative activity.

\section{Product Liability Cost Measures}

The product liability insurance cost measures are drawn from the complete rate-making files of the Insurance Services Office (ISO), an industry consortium for pooling insurance information. The information utilized pertains to product liability coverage purchased by firms for the years 1980-84. Consumers do not pay for this coverage except insofar as the cost is embodied in the product price. This rate-making data base contains over 200,000 records, where the unit of observation is the particular product liability insurance policy that has been written. ${ }^{12}$ Using the product categorizations (which parallel the SIC industry codes), we aggregated the information by industry group to establish a total product liability premium and total product liability loss amount for each three-digit industry code. These data are available for both bodily injury coverage and property damage coverage, and separate variables have been created for each of these components of liability costs. ${ }^{13}$ We divide the aggregate premium and loss data by three-digit industry sales data from the Census of Manufactures.

\footnotetext{
${ }^{12}$ We focus on insurance data for bodily injury and property damage claims using the entire ISO file of insurance premium rates and claims data for product liability coverage. The number of claims and valid records is substantial. For example, in 1980 there were over 20,242 claims involving bodily injury for which there are data on the loss levels.

${ }^{13}$ The recent escalation in liability costs throughout the United States has primarily occurred for the bodily injury component (see Viscusi 1991b).
} 


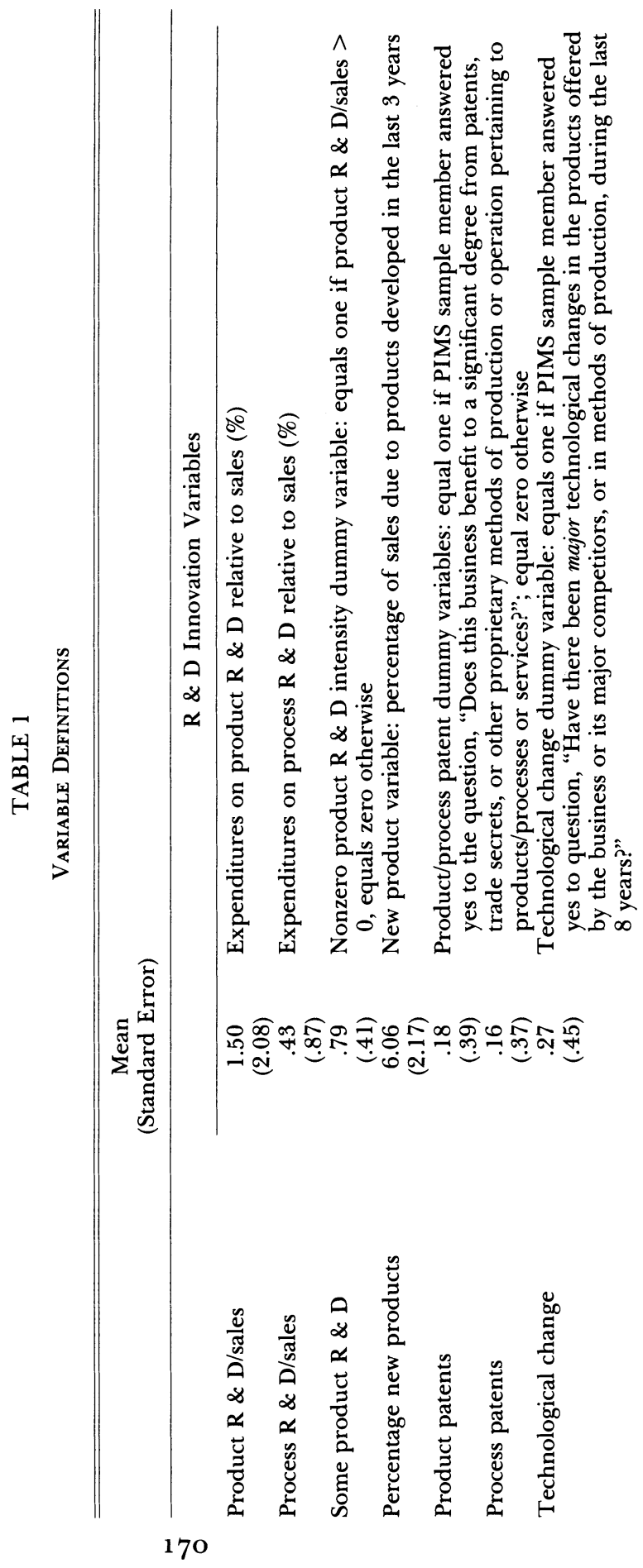




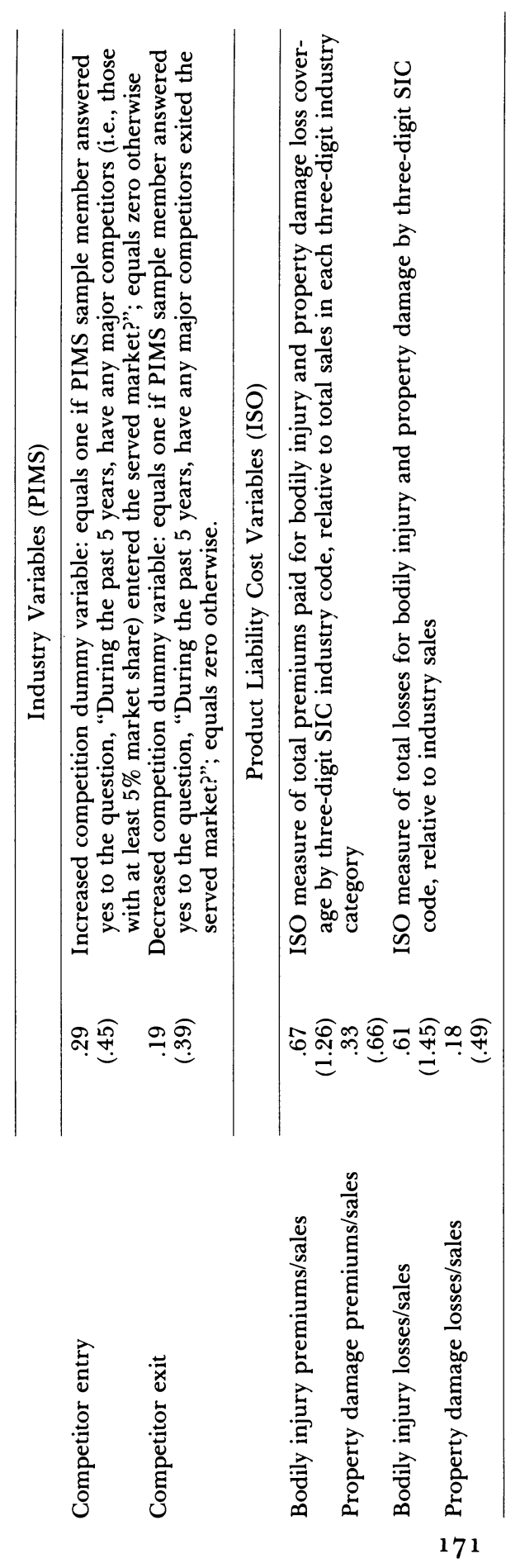


Although these data represent by far the most extensive information pertaining to liability costs, they do not reflect all liability expenses. Firms that self-insure or obtain coverage through a company not affiliated with the ISO will not be represented in this sample. The data consequently provide a partial assessment of the total costs of liability to American industry and can best be regarded as an index of the relative distribution of liability costs across industries, as opposed to a measure of the absolute level of the liability burden. ${ }^{14}$ The liability costs of a product risk to a firm generally consist of the premium costs, the legal fees, and the uninsured costs that may be imposed. Since the ISO data pertain only to premiums and losses, excluding uncovered costs, our measures should be viewed as a proxy for the full liability burden. ${ }^{15}$

A policy written in any given year covers a 2-year period. In setting premium levels, the insurance adjuster relies on the manual rate for the product group and information about the firm's own loss history, as well as adjustments for the firm's current product mix. Premiums consequently are a measure of historical product risk levels and expected risk levels for the current product mix.

The second insurance measure represents losses experienced under a particular policy. Whereas premiums capture expected costs, losses reflect the liability costs actually incurred. These losses in turn will influence future premiums through the experience rating procedure. Losses are charged back to the initial policy year, so that a loss on a product sold in 1980 but for which the losses were incurred in 1983 will appear in the data as a loss in 1980.

For recent policy years (e.g., 1984), all claims that will ultimately be filed on policies written in that year are not yet known. However, these loss and claim levels can be projected using standard actuarial techniques. We have done this using the loss and claim projection factors developed by ISO.

\section{Sample Characteristics}

Table 1 presents means and standard deviations for the variables used in the PIMS/ISO sample. The $\mathrm{R} \& \mathrm{D}$ variables indicate substantial heterogeneity with respect to $\mathrm{R} \& \mathrm{D}$ activities. Product $\mathrm{R} \& \mathrm{D}$ as a percentage of sales (product $\mathrm{R} \& \mathrm{D} /$ sales) equals about 1.5 percent, with a standard error about 50 percent higher than the mean.

\footnotetext{
${ }^{14}$ For additional discussion of this data set, see Viscusi $(1991 b)$ and Viscusi and Moore $(1991 a, 1991 c)$.

${ }^{15}$ If total costs are proportional to total premiums or total losses, then our two measures of insurance will have captured the full liability cost, up to a positive scale factor. This is clearly a best-case assumption that is unlikely to hold.
} 
Twenty-one percent of the firms in the PIMS sample do no product $R$ \& $D$, whereas in some cases $R$ \& $D$ equals 10 percent of sales.

The $\mathrm{R} \& \mathrm{D}$ capital variable measuring whether firms benefit substantially from product patents indicates that about one in every five members of our sample benefits substantially from past R \& D efforts. This does not account for firms that have unpatented trade secrets, however, so that these numbers probably understate the extent of the success of the firm's $R \& D$ projects. The general level of innovative activity at the industry level is captured by the binary technological change variable, which indicates that 27 percent of the firms operate in markets characterized by substantial technological change.

The final $\mathrm{R} \& \mathrm{D}$ variables measure the importance of new products as a component of the firm's sales in the current period. Forty-seven percent of the firms sell some new products, with some firms reporting up to 70 percent of their sales due to new products. Overall, the average contribution of new products to sales is not great.

The product liability cost measures indicate that bodily injury accident costs are greater than property damage losses. The premium measures exceed the loss measures because underwriting costs and allowance for normal industry profits create a spread between premiums and losses.

\section{Empirical Hypotheses}

As indicated above, the empirical analysis focuses on product $R \& D$ intensity as the measure of current innovative activity by the firm. ${ }^{16}$ The basic estimating equation is

$$
\begin{aligned}
\operatorname{product~R~\& ~D~intensity~}_{i t}= & \beta_{0}+\beta_{1} \text { product patents }_{i} \\
& +\beta_{2} \text { technological change }_{i} \\
& +\beta_{3} \text { recent entry }_{i t} \\
& +\beta_{4} \text { recent exit }_{i t}+\gamma_{1} \text { liability }_{i t} \\
& +\gamma_{2} \text { liability }_{i t}^{2}+\varepsilon_{i t} .
\end{aligned}
$$

Time-varying variables are indicated by the $t$ subscript, and $i$ indexes the line of business.

The variable indicating whether the business benefits to a significant degree from product patents captures the role of historical levels of product innovation, or R \& D capital, on R \& D intensity as well as the influence of $\mathrm{R} \& \mathrm{D}$ capital on actual business performance. ${ }^{17}$

\footnotetext{
${ }^{16}$ See Cohen and Levin (1989) for a survey of the literature on the determinants of $R$ \& $D$ intensity.

${ }^{17}$ Clark and Griliches (1984) use a similar formulation. The results in Levin et al. (1987) suggest that this variable is an imperfect indicator of R \& D capital. However, its significance argues for its inclusion as a control variable, particularly since the interpretation of its effect is of secondary importance.
} 
The measure of the importance of technological change to the industry captures industry-specific characteristics of technological change.

The next set of hypotheses pertains to the relationship between innovation expenditures and industry growth. Firms in growing and developing industries typically are in situations in which new product development is likely. We analyze a series of variables pertaining to the industry's growth performance, such as recent entry into the industry and exit from the industry. The entry variable should have a positive effect on innovation $\left(\beta_{3}>0\right)$, and the exit variable should have a negative effect $\left(\beta_{4}<0\right)$.

The first set of liability influences that we explore pertains to the effect of product liability costs on $\mathrm{R} \& \mathrm{D}$ intensity. In the case of safety-related innovation expenditures, one would expect higher liability levels to increase the incentive to invest in safety improvements. Beyond some threshold, liability costs will depress innovation, since the firm will produce inherently risk-free products or withdraw the product. With respect to safety innovation expenditures, therefore, we expect a positive effect at low liability cost levels, which would eventually be dominated by a negative relationship between liability costs and innovation at higher cost levels. In the case of product novelty innovations, we expect higher liability costs to have a negative effect on such innovations through all levels of liability burdens unless they are safety-enhancing. A positive influence of liability on innovation $\left(\gamma_{1}+2 \gamma_{2}\right.$ liability $\left.>0\right)$ indicates a dominant safety effect, whereas a negative influence $\left(\gamma_{1}+2 \gamma_{2}\right.$ liability $\left.<0\right)$ reflects a dominant product innovation discouragement effect. In each case, we expect a negative effect of liability on innovation at high levels of liability $\left(\gamma_{2}<0\right)$.

\section{Empirical Results on R \& D Intensity}

The measures of innovative activity available in the PIMS data can be distinguished according to whether they represent the long-run levels of innovation (i.e., the product patent and technological change variables), current inputs into the innovation process (i.e., the product and process $\mathrm{R} \& \mathrm{D}$ intensity variables), or the current outputs of $\mathrm{R} \& \mathrm{D}$ (i.e., the new product variable). The hypotheses developed in Section IV described a number of expected influences on the R \& D intensity variable, which reflects current $R \& D$ input decisions.

Our analysis considers four distinct measures of the expected product liability cost: premiums for bodily injury and for property damage relative to sales, and losses for bodily injury and for property damage relative to sales. The premium variables constitute more economically meaningful measures of the liability costs faced by firms. Most of the growth in liability costs in the 1980 s related to bodily injuries. 
Table 2 presents ordinary least squares regressions of the product $R$ \& $D$ intensity variable-product $R$ \& $D$ relative to sales-on industry, firm, and liability cost variables. ${ }^{18}$ We include observations with zero $\mathrm{R} \& \mathrm{D}$ intensity here and explore the sensitivity of our results to this treatment in the next section. The liability cost variables-in this case, bodily injury premiums and losses relative to sales, property damage premiums and losses relative to sales, and their squaresshow strong and consistent effects. In both the bodily injury and property damage regressions, liability costs/sales increase product $\mathrm{R} \& \mathrm{D}$ intensity at low risk levels. The nonlinearity of this effect is exhibited by the coefficient on the squared liability cost/sales variable, which is negative and significant (at the .05 confidence level) in two of four cases. Furthermore, the liability variables are always jointly significant.

It appears that at very low liability cost levels, firms have incentives to invest in product safety research in order to reduce these costs, yet still introduce the product to the market. This is the safety incentive effect. When the liability cost levels become sufficiently large, the net effect is negative. This pattern may reflect a product withdrawal effect on safety innovation or a dominant negative influence of the adverse effects of liability on product novelty at high levels of liability. In terms of the model above, $\gamma_{1}>0$ and $\gamma_{2}<0$.

The magnitudes of the liability effects on product $\mathrm{R} \& \mathrm{D}$ intensity are meaningful in a practical sense as well. For example, with the coefficient estimates from the regression of product $R$ \& $D$ intensity on bodily injury losses reported in column 1 of table 2, if liability costs fell from their mean of 0.6 percent to zero, there would be a reduction in product $\mathrm{R} \& \mathrm{D}$ intensity of 0.19 , which represents approximately 12 percent of total $\mathrm{R} \& \mathrm{D}$ intensity. This linear extrap-

${ }^{18}$ We also estimated fixed and random effect versions of our model, controlling for first-order autoregression in the residuals. Because of the unbalanced nature of the PIMS sample, with many of the firms included in only one or two years, and the nature of the risk variable, which changes slowly over time within three-digit industries, we did not expect these techniques to yield precise results. This was borne out in the estimates. We thus rely on the cross-section estimates with time and industry dummies since they are more robust and remain unbiased in the presence of random effects and autocorrelation. The liability variables should be exogenous since they are predetermined. The average lag between the date of an injury and the date of claim closure is 1.5 years. There is an additional lag between the time of product sale and the date of injury. These lags make it unlikely that current $R \& D$ could affect recorded losses and premiums. We tested for the potential endogeneity of the liability cost variables using the Hausman (1978) specification test. Instrumental variables included all the explanatory variables, two-digit industry dummies, and the legal environment variables considered by Viscusi (1990) in his study of the determinants of product liability risk. Test results indicate that the least-squares estimates do not differ significantly from their two-stage counterparts. 


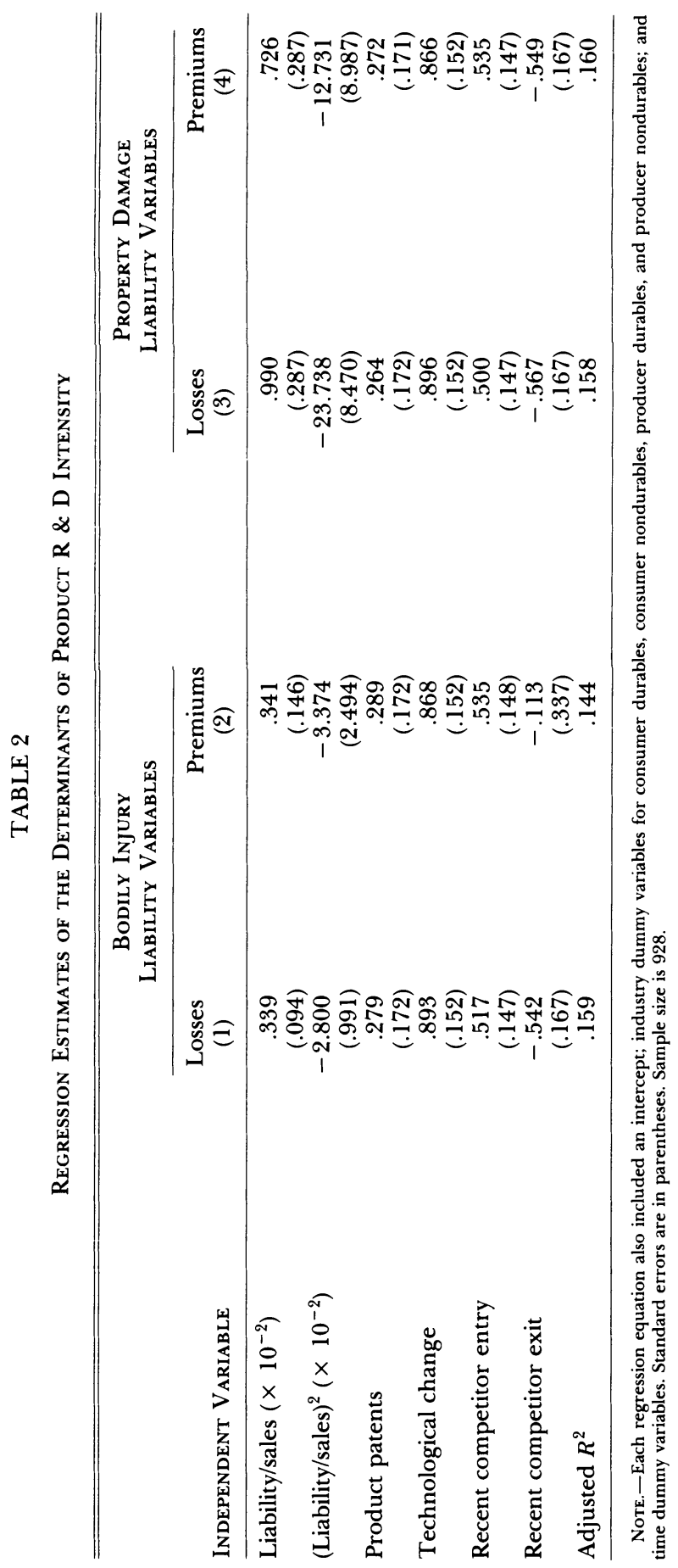


olation, although tenuous, indicates the practical importance of the liability effects. ${ }^{19}$

The equations in table 2 are otherwise consistent with the literature. The industry variables in table 2 indicate more $R \& D$ in healthy industries in which there is increased competition and in industries with technological change, as expected.

The strength of the liability cost effect should differ between process and product $\mathrm{R} \& \mathrm{D}$. Process $\mathrm{R} \& \mathrm{D}$ focuses mainly on changes in the way that goods are manufactured and as a result relates primarily to the manufacturing defect doctrine. In contrast, product $\mathrm{R} \& \mathrm{D}$ and product-related patents relate more to design defects. Most legal scholars attribute the increased liability burden over the past three decades to the expansion of the design defect doctrine rather than to the role of manufacturing defects. Moreover, design defects pose the most substantial risks for a firm, since the firm will face liability for the entire product line rather than for the small percentage of the products that are subject to a manufacturing defect. As a result, for the $\mathrm{R} \& \mathrm{D}$ intensity equations, we expect a much stronger influence of liability on product-related innovation than on processrelated innovation.

Table 3 presents estimates of process $\mathrm{R} \& \mathrm{D}$ intensity regressions that explore this hypothesis. As expected, the effects of product liability costs are not as pronounced here. Only the equation that uses property damage premiums as the liability measure yields significant effects, with a positive value of $\gamma_{1}$ and a negative value of $\gamma_{2}$.

\section{Refinements and Sensitivity Tests}

Two alternative econometric specifications are suggested by our model, which emphasized the importance of corner solutions, and by our data, which indicate that a substantial portion of firms in the PIMS sample report no expenditures on $\mathrm{R} \& \mathrm{D}$. To incorporate these features, we estimated a Tobit model. Following Bound et al. (1984), we also estimated a selectivity-corrected model for firms reporting some R \& D expenditures. As noted by Bound et al., a substantial portion of firms in their National Bureau of Economic Research sample report no $\mathrm{R} \& \mathrm{D}$ whatsoever. Whether this result indicates a corner solution or merely nonreporting of positive expenditures is not clear. They provide some evidence that $\mathrm{R} \& \mathrm{D}$ reporting depends on

${ }^{19}$ The effect of a change in the bodily injury loss/sales ratio of -0.006 would be to change product $\mathrm{R} \& \mathrm{D}$ intensity according to the formula $\Delta(\mathrm{R} \& \mathrm{D} / S)=[33.9-2 \times$ $280.0(P L / S)] \Delta(L / S)$. Evaluated at the midpoint of the interval $[0,0.006]$, this effect equals $(33.9-1.7)(-0.006)$, or 0.19 . 


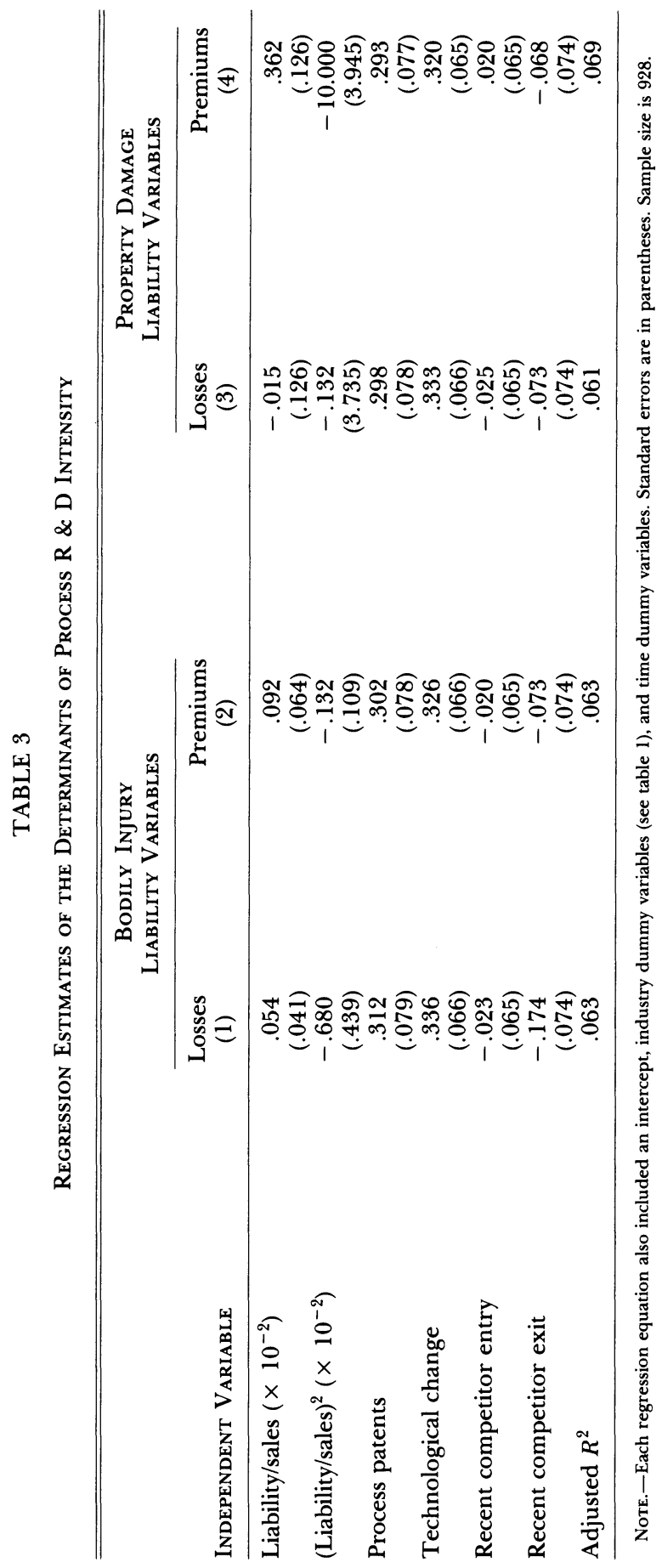


$\mathrm{R} \& \mathrm{D}$ intensity, which is the dependent variable that we use in our regressions. Thus the potential for selectivity bias exists.

Results for alternative estimations indicate that the basic result is very robust. ${ }^{20}$ Significant and positive coefficients are found for each liability measure for both the Tobit and selectivity-corrected models. The magnitudes of the main effects, which are almost uniformly larger than the least-squares estimates, are as expected. ${ }^{21}$

Another robustness test pertains to the dependent variable used. The results in table 2 indicate that product liability costs alter product R \& D intensity, which presumably affects innovation outputs. A more direct measure of the effect of liability costs on new product development can be derived from an analysis of the new products variable. The results, summarized in table 4 , mirror the earlier findings, with three important extensions. First, the percentage new product Tobit regressions include the $R$ \& $D$ intensity variable as a regressor, so that the cost variables capture the effect on innovation given $\mathrm{R} \& \mathrm{D}$ intensity. Second, the new product variable measures the effects of the liability cost on innovation output rather than indirectly through the $\mathrm{R} \& \mathrm{D}$ intensity variable. Third, the nonlinearities are more precisely estimated here, since the quadratic risk term is negative and significant in all eight possible cases. Product liability cost increases innovation at low liability cost levels and decreases it beyond a threshold.

\section{Implications}

It is possible to use the preceding results to compute the $\mathrm{R} \& \mathrm{D}$ maximizing risk levels and to determine which industries in the sample lie beyond these points. For each of these industries, an important implication of our results is that the same level of R \& D intensity could be generated by lower product liability cost, because of the quadratic nature of the $\mathrm{R} \& \mathrm{D}$-liability cost relationship. If the composition of $\mathrm{R} \& \mathrm{D}$ is the same at these two different levels of liability cost, then there may be an efficiency loss. To determine more gener-

${ }^{20}$ These results are presented in detail in Viscusi and Moore (1991b).

${ }^{21}$ Furthermore, the quadratic terms are once again negative and usually significant, indicating that the product withdrawal effect is also quite robust. The selectivitycorrected results also indicate systematic unobservable differences between zero and nonzero R \& D firms. In particular, the coefficient of the mean of the truncated distribution of the error term, $\lambda$, in the positive $R \& D$ intensity equation is significantly different from zero in all four cases. This result is consistent with the findings of Bound et al. (1984). We also find that inclusion of the selectivity bias term has a substantial effect on the magnitudes of the estimated coefficients, which are double their values in table 2 , on average. The net effect of liability costs remains unchanged, however, once the nonlinearities are accounted for. 


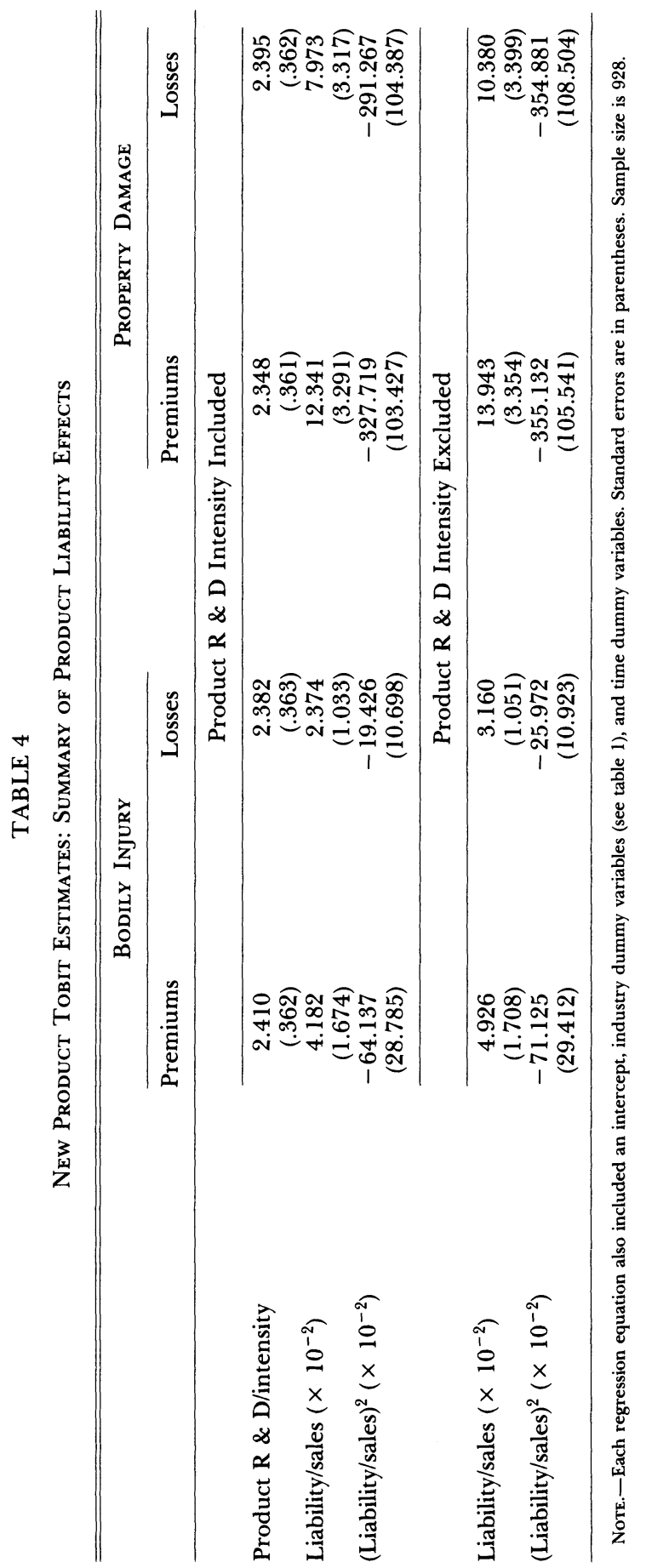


ally whether liability costs should rise or fall requires a case-by-case assessment of the benefits associated with increased product availability, balanced by increases in health losses associated with the existence of dangerous products.

For the bodily injury premium regressions reported in table 2, the risk level corresponding to the peak $\mathrm{R} \& \mathrm{D}$ level occurs at a premium/ sales ratio of about 5 percent. ${ }^{22}$ Similar magnitudes result for the bodily injury loss variable. The maximum level of $\mathrm{R} \& \mathrm{D}$ generated by bodily injury losses occurs at a ratio of bodily injury losses to sales of approximately 6 percent. For the property damage liability effects, which are smaller in magnitude relative to sales, the maximum $\mathbf{R} \& \mathrm{D}$ effects occur at levels of 2 percent for property damage losses and 3 percent for property damage premiums.

On the basis of the ordinary least squares equations in table 2, there are 11 industry groups beyond the point at which liability costs exert a negative effect on innovation. ${ }^{23}$ Although some of these industries may lie beyond the turning point simply because of sampling error in the estimated cost coefficients, the product mix is consistent with our expectations. The industry with the highest liability cost-SIC code 266-is the composition goods industry, which includes manufacturers of asbestos insulation and other fibrous materials. The ratio of bodily injury losses to sales of 14 percent in this industry far exceeds that in any of the other industries in our sample. Asbestos litigation now constitutes over one-half of all litigation in federal courts.

There is also a high liability cost in the miscellaneous chemical products industry, SIC code 289 . This industry produces, among other things, battery acid, fireworks, jet fuel igniters, and pyrotechnic ammunition, all of which are quite risky and associated with high liability levels.

Also at or near the turning point for one or more of the liability variables are the rubber product industry, whose products include tires, a highly litigated product; pottery and related products, which produces bathroom fixtures and cooking ware; miscellaneous fabricated metal products, the industry in which safety valves of various types are produced; the metalworking machinery industry, in which

\footnotetext{
${ }^{22}$ The effect of bodily injury premiums/sales $(\mathrm{BIP} / S)$ on $\mathrm{R} \& \mathrm{D}$ intensity $(\mathrm{R} \& \mathrm{D} / S)$ is $\partial(\mathrm{R} \& \mathrm{D} / S) / \partial(\mathrm{BIP} / S)=34.1-[2 \times 337.4 \times(\mathrm{BIP} / S)]$. Equating this expression to zero and solving for $\mathrm{BIP} / S$ yield the ratio $\mathrm{BIP} / S=0.05$.

${ }^{23}$ Earlier results reported in Viscusi and Moore $(1991 c)$ indicated that a small number of manufacturing industries were above the point beyond which increases in product liability reduce $\mathbf{R} \& \mathbf{D}$ expenditures. These included the machine bolt and screw industries, construction, and some service industries. The results reported here add a number of auxiliary control variables and include only manufacturing firms.
} 
products such as hand-held power tools, metal-cutting machine tools, and welding equipment are produced; the special machinery industry, in which sawmill machines, band saws, and food slicers are produced; electrical industrial apparatus; laboratory apparatus; and miscellaneous manufacturing. Of particular note is the miscellaneous manufacturing industry, whose products include book matches, which have been the subject of product safety regulation, and cigar and cigarette lighters, which are heavily litigated.

\section{Conclusions}

The empirical relationship between product liability cost and research and development on new products suggests systematic linkages consistent with previous evidence on specific products such as vaccines. Product liability costs increase product R \& D intensity initially, but the effect eventually becomes negative. Several manufacturing industries are located beyond the point at which $R \& D$ intensity is maximized. For these products, the same $\mathrm{R} \& \mathrm{D}$ level could be achieved for a lower product liability burden. However, this conclusion focuses only on average industry effects, not the composition of the R \& D or the potential desirability of the withdrawal of some specific risky products.

It is not possible with our data to distinguish the effects of product liability on safety-related $\mathrm{R} \& \mathrm{D}$ expenditures and on the development of new varieties of the product. It is clear, however, that net expenditures on product $\mathrm{R} \& \mathrm{D}$ relative to sales rise with increases in product liability costs up to some level and that the portion of sales due to new products is similarly affected. We infer from these results that the development of new, safer products is the primary outcome engendered by the recent growth in the cost of product liability to firms. Whether these safety improvements represent efficiency gains depends on the underlying liability doctrines and their application by the courts.

The product liability-innovation relationship is much stronger for product $R$ \& $D$ than for process $R$ \& $D$. This coincides with the prevailing view that expansion of the design defect doctrine, rather than the manufacturing defect doctrine, has contributed to the increased role of product liability. These results also suggest that our estimates are capturing the role of liability costs rather than some other aspect of product quality.

Although the findings presented here do not indicate the overall desirability of changes in legal rules, they do highlight clear-cut effects that may enhance or hinder overall social welfare. Perhaps even more important, they identify a strong relationship between liability 
and innovation that has made the courts a major player in the product innovation process.

\section{References}

Bound, John; Cummins, Clint; Griliches, Zvi; Hall, Bronwyn H.; and Jaffe, Adam. "Who Does $\mathrm{R} \& \mathrm{D}$ and Who Patents?" In $R$ E $D$, Patents, and Productivity, edited by Zvi Griliches. Chicago: Univ. Chicago Press (for NBER), 1984.

Clark, Kim B., and Griliches, Zvi. "Productivity Growth and R \& D at the Business Level: Results from the PIMS Data Base." In $R \in \mathcal{E} D$, Patents, and Productivity, edited by Zvi Griliches. Chicago: Univ. Chicago Press (for NBER), 1984.

Cohen, Wesley M., and Levin, Richard C. "Empirical Studies of Innovation and Market Structure." In Handbook of Industrial Organization, vol. 2, edited by Richard Schmalensee and Robert Willig. Amsterdam: North-Holland, 1989.

$\rightarrow$ Epple, Dennis, and Raviv, Artur. "Product Safety: Liability Rules, Market Structure, and Imperfect Information.” A.E.R. 68 (March 1978): 80-95.

$\rightarrow$ Goldberg, Victor P. "The Economics of Product Safety and Imperfect Information." Bell J. Econ. and Management Sci. 5 (Autumn 1974): 683-88.

Hausman, Jerry A. "Specification Tests in Econometrics." Econometrica 46 (November 1978): 1251-71.

Kitch, Edmund W. "Vaccines and Product Liability: A Case of Contagious Litigation." Regulation 9 (May/June 1985): 11-18.

Landes, William M., and Posner, Richard A. The Economic Structure of Tort Law. Cambridge, Mass.: Harvard Univ. Press, 1987.

Levin, Richard C.; Klevorick, Alvin K.; Nelson, Richard R.; and Winter, Sidney G. "Appropriating the Returns from Industrial Research and Development." Brookings Papers Econ. Activity, no. 3 (1987), pp. 783-820.

National Academy of Sciences. Developing New Contraceptives: Obstacles and Opportunities. Washington: Nat. Acad. Press, 1990.

$\rightarrow$ Oi, Walter Y. "The Economics of Product Safety." Bell J. Econ. and Management Sci. 4 (Spring 1973): 3-28.

$\longrightarrow \rightarrow-$. "The Economics of Product Safety: A Rejoinder." Bell J. Econ. and Management Sci. 5 (Autumn 1974): 689-95.

Polinsky, A. Mitchell. An Introduction to Law and Economics. 2d ed. Boston: Little, Brown, 1989.

Ravenscraft, David, and Scherer, F. M. "The Lag Structure of Returns to Research and Development." Appl. Econ. 14 (December 1982): 603-20.

Shavell, Steven. Economic Analysis of Accident Law. Cambridge, Mass.: Harvard Univ. Press, 1987.

Spence, A. Michael. "Consumer Misperceptions, Product Failure and Producer Liability." Rev. Econ. Studies 44 (October 1977): 561-72.

Viscusi, W. Kip. "The Performance of Liability Insurance in States with Different Products-Liability Statutes.” J. Legal Studies 19, no. 2, pt. 2 (1990): 809-36.

$\longrightarrow \rightarrow$-. "Product and Occupational Liability." J. Econ. Perspectives 5 (Summer 1991): 71-91. (a)

1991. (b) 
Viscusi, W. Kip, and Moore, Michael J. "An Industrial Profile of the Link between Product Liability and Innovation." In The Liability Maze: The Impact of Liability Law on Safety and Innovation, edited by Peter W. Huber and Robert E. Litan. Washington: Brookings Inst., 1991. (a)

"Product Liability, Research and Development, and Innovation." Working paper. Durham, N.C.: Duke Univ., 1991. (b)

"Rationalizing the Relationship between Product Liability and Innovation." In Tort Law and the Public Interest: Competition, Innovation, and Consumer Welfare, edited by Peter H. Schuck. New York: Norton, 1991. (c) 